\title{
A COMPREENSÃO RESPONSIVA ATIVA NAS POSTAGENS \#ELENÃO / \#ELESIM POR OCASIÃO DO PLEITO ELEITORAL DA CANDIDATURA DE JAIR MESSIAS BOLSONARO PARA A PRESIDÊNCIA DA REPÚBLICA DO BRASIL
}

\author{
BOLSONARO PARA A PRESIDÊNCIA DA REPÚBLICA DO BRASIL \\ THE RESPONSIVE UNDERSTANDING ACTIVE IN THE POSTS \# ELENÃO / \#ELESIM ON \\ THE OCCASION OF THE ELECTORAL CLAIM OF THE JAIR MESSIAS BOLSONARO \\ CANDIDACY FOR THE PRESIDENCY OF THE REPUBLIC OF BRAZIL
}

Selmo Alves dos Santos ${ }^{1}$

RESUMO: Nesse artigo, tem-se o objetivo de discutir a Compreensão Responsiva Ativa dos pressupostos teóricos de herança bakhtiniana, a partir do confronto das hashtags “\#elenão" / "\#elesim” veiculadas em ambientes virtuais, com enfoque na interação verbal no contexto do processo dialógico entre os interlocutores investidos nas ações de aprovação e desaprovação da candidatura do presidenciável Jair Messias Bolsonaro.

Palavras-chave: Compreensão Responsiva Ativa. Dialogicidade. Ambiente virtual.

ABSTRACT: In this article, the objective is to discuss the Active Responsive Understanding of the theoretical assumptions of Bakhtinian inheritance, based on the confrontation of the hashtags "\# elenão" / "\#elesim" transmitted in virtual environments, with a focus on verbal interaction in the context of the process dialogical between the interlocutors invested in the actions of approval and disapproval of the candidacy of the presidential candidate Jair Messias Bolsonaro.

Keywords: Active Responsive Understanding. Dialogicity. Virtual environment.

As hashtags contrárias à candidatura de Jair Messias Bolsonaro “\#elenão" e variações postadas nos meios digitais por ocasião do pleito eleitoral para a Presidência da República do Brasil de 2018 logo motivaram, como resposta, manifestações de apoio ao

\footnotetext{
I Universidade Federal da Bahia (UFBA). E-mail: profselmoalves@yahoo.com.br.
} 
candidato, nas mesmas redes sociais, através da hashtag “\#elesim”. O confronto das referidas mensagens no contexto do processo dialógico entre os interlocutores investidos nas ações de aprovação e desaprovação da candidatura da presidenciável evidência não apenas uma relação interativa de locutores imediatos, mas também entre os outros discursivos mediatos da relação dialógica (BAKHTIN, 2006).

Para o autor, a enunciação é o produto da interação verbal de dois indivíduos socialmente organizados, mesmo que não haja um interlocutor real. Com a ampliação das redes digitais na contemporaneidade, verifica-se que as interações, no caso em tela, ocorrem tanto entre sujeitos conhecidos como desconhecidos, de diferentes perfis. Entende-se que tal fato pode ser explicado à luz da categoria de análise - Compreensão Responsiva Ativa-, sendo esta uma orientação filosófica da linguagem criada por esse autor.

Para Bakhtin (op. cit.), todo ato de compreensão é uma resposta, sendo amplo o seu conceito de resposta, por ultrapassar o esquema já padronizado de que para toda pergunta se exige uma resposta, uma vez que a resposta na teoria bakhtiniana permite uma atitude na qual determinado interlocutor se posiciona ideologicamente sobre determinado discurso. Tal posicionamento ideológico não é visto como uma réplica a uma pergunta, pura e simplesmente, mas trata-se, sobretudo, de uma resposta a um discurso, que pode ser mediato ou imediato, conforme já mencionados acima. Menegassi (2006) categoriza a atitude responsiva de duas outras formas, interna ou externa. É interna, quando o sujeito conversa consigo mesmo sobre o texto que produziu; é externa, quando ele torna explícita a sua ideia, a fim de que as pessoas a vejam e possam manifestar uma compreensão e uma resposta a respeito.

Bakhtin (1997) considera que a cada palavra da enunciação em processo de compreensão pelo outro faz corresponder uma série de outras palavras desse sujeito. Nessa perspectiva, entende-se que compreender não é apenas se posicionar discursivamente sobre determinado fenômeno discursivo, mas é fundamentalmente um ato de se apropriar dos discursos do outro para a constituição da própria enunciação; é, enfim, contra- 
argumentar o discurso do outro com suas próprias palavras. Esse autor afirma que compreender é opor à palavra do locutor uma contrapalavra. Isso implica dizer que compreender é usar um discurso anterior para a formação de um discurso-resposta. Nessa perspectiva, Bakhtin (op. cit.) afirma que - toda compreensão é prenhe de resposta -. A compreensão responsiva, portanto, nada mais é do que a fase inicial e preparatória para uma resposta.

Compreender é responder a um determinado enunciado concreto, o que, para o autor, cada enunciado é um elo da cadeia complexa de outros enunciados. Logo, não há enunciados ou discursos isolados, e o locutor não é uma espécie de Adão bíblico que nomeia o mundo pela primeira vez. Cada homem encontra o mundo e seus discursos já existentes, mas não acabados. Assim, o locutor terá uma autonomia relativa em relação a tais discursos, porém será também um respondente desses enunciados. É baseado na concepção de autonomia relativa que Zozzolli (2002) postula a existência do sujeito relativamente autônomo, e Cavalcante (1999) conceitua a ideia de sujeito responsivo ativo. Permite-se dizer que, por mais que os sujeitos discursivos tomem posições em relação a um discurso, a ponto de entender que o discurso é interior (diálogo consigo mesmo) ou próprio, tal enunciado é influenciado por outros discursos ou fatores externos.

Logo, só é possível compreender um enunciado alheio, quando se reage às palavras dos discursos alheios, de tal forma como teorizou Bakhtin (1997), que essa reação se dá quando as palavras despertam nos sujeitos ressonâncias ideológicas ou concernentes à vida.

Os discursos, por mais que pareçam próprios de cada locutor, estão contaminados por outros discursos. Outras vozes se fundem às vozes de cada locutor de forma a parecer que são suas essas vozes, a ponto de esquecerem que essas vozes já estavam presentes no mundo ideológico antes de o "seu discurso" vir existir. Aí reside a razão de algumas vezes o locutor reforçar o que diz, concordar ou discordar e/ou usar as palavras do outro como se nelas estivessem seus próprios propósitos. 
Bakhtin (1998) enfatiza que o discurso se encontra no discurso de outrem e não pode deixar de participar da interação viva e tensa. Assim, compreensão ativa não se restringe a entender a significação morfossintática, fonética e/ou semântica da palavra.

Nesse sentido, pode-se afirmar, por exemplo, que a palavra, conforme Bakhtin (1997), não possui entonação, pois, se a possuísse, deixaria de ser uma simples palavra e passaria a ser um enunciado. É o que ocorre, por exemplo, com as trocas das hashtags “\#elenão” / “\#elesim”, em manifestações de confronto, as quais, em um contexto isolado, não possuiriam nenhuma entonação. Somente em determinado contexto o uso dessas expressões poderá apresentar entonação e, desse modo, elas deixam de ser meras expressões e passam a ser enunciados. Logo, a palavra é desprovida de emoções e juízo de valor, mas seu uso contextual é que lhe pode atribuir tudo isso. De forma isolada, as palavras não possuem significação, visto que é exatamente na responsividade e/ou no diálogo com a palavra do outro que se estabelece a significação.

A palavra está ligada intimamente à vida, e é na vida que as palavras tomam existência, assim como é na dialogicidade entre os interlocutores e seus discursos que a palavra se constitui. A língua penetra na vida através dos enunciados concretos que a realizam, e é também através dos enunciados concretos que a vida penetra na língua. Assim, a vida se utiliza da língua e a língua se utiliza da vida para buscar sentido de existência. Conforme Bakhtin (op. cit.), a vida começa apenas quando uma enunciação encontra outra. Nesse sentido, a palavra não pode ser vista como neutra, por estar a serviço de qualquer locutor ou de qualquer juízo de valor, que pode ser totalmente diferente ou até mesmo contrário quanto à função ideológica, ou seja, a palavra não possui uma função ideológica específica, e é a situação de uso que lhe dará uma função, que pode ser estética, científica, moral, religiosa, dentre outras funções.

Assim, o uso da palavra pelo interlocutor se constitui numa resposta, como também o próprio silêncio se constitui em uma compreensão e, por assim dizer, a compreensão ou resposta ativa, uma vez que Bakhtin (2006) não admite a possibilidade de haver compreensão passiva, sendo esta condição o que ele chama de elemento abstrato de um 
fato real. Cada ação humana envolve sempre uma reação do outro, e isso ocorre porque, no sujeito, há uma necessidade de provocação a atitudes discursivas no outro, pelo fato de os sujeitos se constituírem no diálogo.

É preciso destacar no contexto da teoria bakhtiniana, em especial no dialogismo, a transferência de palavra ou alternância de sujeito do discurso, o que a Análise da Conversação vai denominar de passagem de turnos conversacionais. Sobre esse aspecto, evidenciam-se tais eventos discursivos nas hashtags “\#elenão” / “\#elesim”, trocadas por usuários contra e a favor do candidato Bolsonaro.

Bakhtin (2003, p. 27I), ao afirmar que - "toda compreensão é prenhe de resposta" e, de uma forma ou de outra, forçosamente a produz, e o ouvinte torna-se o locutor, quer esse autor referir-se à alternância de papéis entre o locutor e o seu interlocutor, e o que se confirma aí é que não pode haver compreensão responsiva ativa sem resposta, pois ambas estão unidas uma a outra. Desse modo, a compreensão é ativa, quando a resposta de um dos sujeitos da interação é imediata e situada, e ainda que seja silenciosa, ela também é ativa, quando um dos sujeitos da interação não responde de forma imediata, mas retarda a resposta, ocasionada pela reelaboração da resposta ou do discurso.

As manifestações dos interlocutores por meio das hashtags, enquanto textos, são consideradas unidades de comunicação verbal, ou enunciados concretos, de acordo com a perspectiva sócio-histórica e dialógica de Bakhtin (2003) para o estudo dos gêneros do discurso.

Nesse sentido, os enunciados, ou unidades concretas de comunicação, são elaborados e organizados de acordo com cada esfera da atividade humana mediante tipos relativamente estáveis de enunciados, denominados gêneros do discurso. Tais enunciados caracterizam os gêneros a partir do seu conteúdo temático, estilo verbal e de construção composicional, que, por sua vez, refletem as condições específicas e as finalidades das esferas da atividade humana. Isso permite dizer que o falante de uma língua dada já dispõe de um repertório de gêneros e os emprega com base no conhecimento que adquire na sua língua materna. 
Portanto, para esse autor (op. cit.), são caras palavras como - interação verbal, enunciado concreto, signo ideológico e dialogismo -, advindas do seu Círculo. Utiliza-se a expressão Círculo de Bakhtin porque as formulações e as obras são produto de reflexão de um grupo de intelectuais. Como lembram Brait e Campos (2009, p.17):

\begin{abstract}
A questão das assinaturas e da composição do Círculo tem variado do extremo da negação intelectual de V. N. Volochínov (1895-1936), P. Medvedev (1892-1938), I. Kanaev (1893-1983), M. Kagan (1889-1934), L. Pumpianskii (1891-1940), M. Yudina (1899-1970), K. Vaguinov (1899-1934), I. Sollertinski (1902-1944), B. Zubakin (1894-1937) às dúvidas em torno da autenticidade de determinadas ideias e conceitos considerados genuinamente bakhitinianos.
\end{abstract}

As questões que cercam a compreensão responsiva ativa nas hashtags "\#elenão" / “\#elesim” produzidas em ações favoráveis e desfavoráveis à candidatura do presidenciável Jair Messias Bolsonaro por ocasião do pleito eleitoral do Brasil de 2018, diante dos posicionamentos ideológicos dos interlocutores nas hashtags contrárias e favoráveis fazem instaurar o diálogo entre os interlocutores (reais ou presumidos), que se materializa por meio de enunciados concretos de sujeitos sócio-historicamente situados e de formulações de vozes e posicionamento nas hashtags.

A responsividade ativa evidenciada nas hashtags “\#elenão" / “\#elesim” entre os interlocutores indica que os referidos enunciados se refletem na vida cotidiana dos sujeitos, assim como nas atitudes observadas em decorrência de tais usos. O confronto dos enunciados com a realidade concreta dos sujeitos necessita levar em conta a dinâmica dos discursos e a sua natureza socialmente construída e em uso. Desse modo, compreende-se que a realidade fundamental da língua é a interação verbal, que se materializa por meio de enunciados concretos de sujeitos sócio-historicamente situados. O discurso, por assim dizer, é a língua em sua integridade concreta e viva.

A comunicação via rede social tão difundida nos últimos anos permite perceber a influência da linguagem utilizada nesses ambientes em textos de diferentes gêneros digitais, a exemplo do Twitter, também chamado microblogging, que se expandiu para 
outros gêneros afins no contexto virtual, o que inclui o uso de hashtags e inovações linguísticas, devido à sua alta frequência e visibilidade. Conforme Zappavigna (2014), o ato de se escrever mensagens curtas para se publicar na internet com o objetivo de interagir no ambiente virtual se tem tornado uma prática social muito difundida e, por isso mesmo, merece atenção.

É possível observar diversas formas de uso das hashtags, como aponta Caleffi (2015). Há mensagens publicadas no gênero microblogging, que contam com o uso excessivo de hashtags e que, muitas vezes, apresentam várias palavras isoladas marcadas, quase como se fosse uma espécie de "mania" no hábito de se publicar textos online. As hashtags podem servir, ainda, para acrescentar contexto a uma mensagem ou conferir maior profundidade e ênfase ao que foi escrito, negar algo que tenha sido declarado, expressar emoções, apoiar movimentos e promover marcas.

Para Caleffi (2015), o ato de se adicionar o símbolo \# a uma palavra ou frase, valese, possivelmente, de um novo processo morfológico (hashtagging), que consiste em um mecanismo de formação de uma grande variedade de itens linguísticos a partir da adição do elemento \#.

Zappavigna (2015) analisa o uso das hashtags como instrumentos de metadados sociais, que, em vez de atuarem apenas com o gerenciamento e organização de informações (uso das hashtags como marcadores de tópicos que indicam o assunto de um texto inserido em mídias sociais), elas também operam a serviço das relações sociais interpessoais. Segundo a linguista australiana, o símbolo \# pode estar associado a três funções específicas que podem ser interpretadas da seguinte forma: i) Hashtags experienciais: se referem à função das hashtags de catalogar assuntos (função classificatória); ii) Hashtags interpessoais: se referem à função de avaliar, prestar julgamento - "metacomment"; iii) Hashtags textuais: se referem aos marcadores usados para a organização dos textos no contexto do microblog, ou seja, as hashtags podem apontar se um texto se trata do tema da discussão ou se é uma informação nova. 
As mensagens veiculadas mediante o uso de hashtags se fazem notórias com o objetivo de produzir força aos contextos, o que, fora da realidade virtual, dificilmente produziriam o mesmo efeito. Partindo-se do pensamento bakhtiniano, verifica-se a responsividade ativa nas hashtags “\#elenão" / “\#elesim”, enquanto materialização de discursos que, por sua vez, estão inseridos em uma prática social.

As mensagens “\#elenão” / “\#elesim” resultam da junção do pronome pessoal com os advérbios de negação e de afirmação, respectivamente, que buscam convidar o eleitor a participar, repensar seu voto ou contribuir para o movimento em questão. No entanto, o que se verifica, de fato, nas mensagens, é que o aspecto semântico se altera na presença do recurso linguístico \#, pois, neste formato, a mensagem agora compreende a ideia de movimento a ser adotado e o fato de que o usuário adotou o movimento, de aprovação ou de desaprovação. Dessa forma, o uso da hashtag acrescido dos conteúdos "elenão" / “elesim”, já é, em si, uma forma de participar do movimento e promover uma prática social.

Os sujeitos responsivos ativos constituídos nas mensagens “\#elenão” / "\#elesim” postadas em ambientes virtuais abertos e/ou fechados configuram-se nos fenômenos discursivos por eles produzidos, a partir dos usos concretos observados, confirmando a responsividade e, por conseguinte, a existência da linguagem enquanto práticas situadas. $\mathrm{O}$ termo "situadas" é aqui pensado sob a óptica das interações entre os sujeitos, ou seja, situada na linguagem e situada no contexto físico (GHERARDI, 2008).

Assim, a compreensão ativa é um arquétipo de dialogicidade, em que o próprio indivíduo recebe a mensagem de forma idiossincrática, sem reação alguma e, em seguida, manifesta-se ativamente em uma situação enunciativa. A compreensão responsiva ativa de um enunciado concreto é uma orientação discursiva em que o primeiro locutor toma direcionamento levando em consideração o também posicionamento discursivo do seu interlocutor ou o outro do discurso.

No caso das hashtags em estudo, admite-se a hipótese de que a compreensão responsiva ativa atravessa os acontecimentos discursivos nelas materializados. Acredita-se 
que as hashtags, marcadas por enunciados de cunho político-partidário, assumem grande força enunciativa, constituindo-se, por isso mesmo, em alvo de comentários e questionamentos de natureza diversa, misturando as esferas pública e privada, tanto do candidato ao cargo eletivo, objeto das ações, quanto dos próprios interlocutores. Para Bakhtin (1997, p. 280), "As esferas da atividade humana, por mais variadas que sejam, estão sempre relacionadas com a utilização da língua". Com isso, a análise das referidas hashtags evidência, entre outras questões, a responsividade ativa e os seus níveis, além de outros efeitos produzidos, a partir de pressupostos bakhtinianos, já mencionados.

Nesse contexto, verifica-se que o elo da cadeia enunciativa resulta das relações que se estabelecem nas redes sociais através das ações de curtir, compartilhar, comentar, retweetar, especificamente por meio de ações responsivas nas postagens em estudo. Portanto, conforme Rojo e Barbosa (2015, p.120-121):

\footnotetext{
Nunca antes a ideia de que o enunciado é um elo da cadeia verbal que remete a (e se trama a partir de ou nos) enunciados ulteriores, a postulação de responsividade ativa no cerne dos atos de compreensão e a concepção bakhtiniana de autoria - como orquestração de vozes - puderam ser tão evidenciadas quanto com as novas mentalidades, mídias e ambientes.
}

Esse contexto de remixagem, que resulta em gêneros híbridos, vai ao encontro da relativa estabilidade dos gêneros que vão se transformando historicamente para atender às necessidades comunicativas contemporâneas dos sujeitos. E é exatamente através do arcabouço teórico bakhtiniano que tanto tem inspirado e iluminado diversas teorias relacionadas à linguagem, que se verifica a responsividade ativa dos sujeitos a veiculação de mensagens produzidas nas hashtags “\#elenão" / “\#elesim”.

\section{REFERÊNCIAS}

BAKHTIN. M. Estética da Criação Verbal. Tradução: M.E.Galvão. 2. ed. São Paulo: Martins Fontes, 1997.

Marxismo e Filosofia da linguagem. Tradução: Michel Lahud e Yara Frateschi Vieira. São Paulo: Hucitec, 2006. 
Os gêneros do discurso. In: Estética da criação verbal. São Paulo: Martins Fontes, 2003.

. Para uma Filosofia do Ato. Tradução: Carlos Alberto Faraco Cristóvão Tezza. Austin: University of Texa Press, 1993.

Problemas da poética de Dostoievski. Tradução: Paulo Bezerra. 2. ed. Rio de Janeiro: Forense-Universitária, 1997.

. Questões de Estética e de Literatura. 3. ed. S. Paulo: UNESP/Hucitec, 1993.

BRAIT, B.; CAMPOS, M. I. B. Da Rússia czarista à web. In: BRAIT, B. (Org.). Bakhtin e o Círculo. São Paulo: Contexto, 2009, p. 15-30.

CALEFFI, P-M. The 'Hashtag': a new word or a new rule? Journal of Theoretical Linguistics. v. 13, n.2, p. 46-69, 2015.

CAVAlCANTE, Maria do Socorro Aguiar de Oliveira. O Sujeito Responsivo / Ativo Em Bakhtin e Lukács, - "A língua sob o olhar da Análise do Discurso” In: MOURA, Maria Denilda (Org:) - Os múltiplos usos da língua, Maceió, EDUFAL,I999.

GHERARDI, Silvia. Situated knowledge and situated action: what do practice-based studies promise? In: In: BARRY, D.; HANSEN, H. New approaches in management and organization. London: SAGE, 2008.

KOZINETS, R. V. Netnografia: realizando pesquisa etnográfica online. Tradução de B. Daniel. Porto Alegre: Editora Penso (Obra original publicada em 2010), 2014.

MENEGASSI, R.J. Aspectos da responsividade na interação verbal. Línguas dr Letras. Unioeste. Cascavel/PR.v. Io.n. I8. P. I47-I70. I. Sem. 2006.

ROJO, R.; BARBOSA, J. P. Hipermodernidade, multiletramentos e gêneros discursivos. São Paulo: Parábola Editorial, 2015.

ZAPPAVIGNA, M. Ambient Afilliation in Microblogging: Bonding around the Quotidian. Media International Australia, Incorporating Culture \& Policy, v.15I, May 2014, p.97-103, 2014 .

Searchable talk: The linguistic functions of hashtags in tweets about Schapelle Corby. Global Media Journal (Australian Edition), v.9, n.I, 2015. 
ZOZZOLI, R. M. D. (org.). Ler e produzir - discurso, texto e formação do sujeito leitor/produtor. Maceió: Edufal, 2002. 